\title{
Antihepatotoxic and antioxidant defense potential of Mimosapudica
}

\author{
Nazeema T.H. ${ }^{1}$ and Brindha V. ${ }^{2^{*}}$ \\ ${ }^{1}$ Department of Biochemistry, RVS College of Arts and Science, Coimbatore, Tamil Nadu, India \\ ${ }^{*}$ Department of Biochemistry, PSG College of Arts and Science, Coimbatore, Tamil Nadu, India, \\ brindhavenkatesh@ymail.com
}

\begin{abstract}
Reactive Oxygen species (ROS) are believed to be responsible for pathogenesis of various diseases affecting tissues and the main organ, the Liver. Hence, in the present study, the extent of Lipid Peroxidation (LPO) and ROS elimination and its defense mechanisms by the enzymic \& non enzymic antioxidants in liver \& serum was investigated. Hepatoxicity was manifested by significantly decreased $(p<0.05)$ levels in the activities of the enzymic antioxidants such as Superoxide dismutase (SOD) Catalase (CAT), Glutathione peroxidase and the non enzymic antioxidants such as glutathione \& Vitamin C in rats induced hepatic damage by ethanol Simultaneous administration of the leaf extract Mimosa pudica along with the toxin ethanol in rats showed a considerable protection against the toxin induced oxidative stress and liver damage as evidence by a significant increase $(p<0.05)$ in antioxidant activities. The study reveals that the co administration of Mimosa pudica aqueous extract significantly lowered the level of lipid peroxidation in alcohol fed mice.
\end{abstract}

Key words- Mimosa pudica, Hepatoxicity, antioxidants

\section{Introduction}

Liver damage due to consumption of alcohol may be caused by oxygen radicals such as superoxide and hydroxyl radicals generated during the metabolism of ethanol by the microsomal oxidising system [1]. Antioxidants are likely to provide beneficial effects on hepatocytes desensitization against oxidant stress while inhibiting primary mechanism for expression of pro-inflammatory and cytotoxic mediators [2]. In spite of tremendous scientific advancement in the field of hepatology in recent years, liver problems are on the rise. [3]. Ingested alcohol produces striking metabolic imbalances in the liver and leads to the formation of reactive oxygen species [4] and free radial increase [5]. The free radical produced during the metabolism of the drug is considered to be responsible for alteration induced in lipid peroxidation, enzymic \& non enzymic antioxidants [6]. Antioxidants stop the free radical from forming in the first place or interrupt an oxidizing chain reaction to minimize the damage caused by free radicals [7]. Medicinal plants are considered to be an important source of antioxidant compounds and the therapeutic benefit of many medicinal plants in often attributed to their antioxidant properties [8]. Mimosa pudica is an annual shrub found through out India. Stem and rachis are clothed with prickles arising from bulbous bases. Previous studies have shown that Mimosa pudica cures congestion with flem, biliousness, leucoderma and diseases of blood [9]. The present study investigates Mimosa pudica used in herbal medicine for their potential to scavenge free radicals as consequence may be considered as effective sources for combating oxidative hepatic damage [10]. Although a number of reports described the usefulness of this herb against various disorders, no studies have been published to date describing its beneficial role against ethanol induced hepatotoxicity in rats. In this study, the extent of liver damage was assessed by determining the hepatic antioxidant status by measuring the hepatic content of SOD, GSH, CAT, Reduced glutathione Vitamin $\mathrm{C}$ and TBARS expressed as malanoldialdehyde equivalents.

\section{Materials and Methods \\ Animals}

Male albino Wister rats (150 gm) were housed in large spacious cages and were fed on standard pellet diet (M/s Hindustan Lever Ltd.,) and water and libitum. The experimental procedures were carried out in strict compliance with the Animal Ethics committee's rules and regulations of this institute.

\section{Plant Material}

The plant material was taxonomically identified by Prof. Parthiban, Associate, Prof. (Forestry), TNAU, Tamil Nadu, India.

\section{Experimental Design}

The rats were divided into four groups $(n=4)$. The ethanol dose for rats was calculated on the basis of their body weight

Group I:

Control - Normal Healthy Rats with control vehicle i.e., distilled water.

Group II:

Alcohol Control - Rats administered with $40 \%$ alcohol orally.

Group III:

Simultaneous Induction and Treatment - (Alcohol + Aqueous extract) Simultaneous administration of $40 \%$ alcohol and aqueous plant (Mimosa pudica) extract ( $1 \mathrm{gm} / \mathrm{kg}$ body wt.) was given orally. 
Group IV:

Aqueous Extract Control - Rats administered with aqueous extract (1 $\mathrm{gm} / \mathrm{kg}$ body wt.) of the plant Mimosa pudica orally.

Preparation of Sample for Antioxidant Studies After the end of the experimental period of 30 days the rats were deprived of food over night and sacrificed by cervical dislocation. Blood was collected and kept for 30 minutes without disturbing. The blood clots were then centrifuged for 15 minutes at $2000 \mathrm{rpm}$ to separate the serum and it is used for antioxidant analysis. The liver was washed with ice cold tris buffered saline, blotted dry and $10 \%$ homogenate was prepared using tris buffered saline ( $\mathrm{pH} \mathrm{7.4)} \mathrm{to} \mathrm{follow} \mathrm{lipid}$ peroxidation rate. $15 \%$ homogenate were prepared using phosphate buffered saline $(\mathrm{pH}$ 7.0) in cold condition for the estimation of antioxidants and $20 \%$ liver homogenate was prepared using 5\% trichloroacetic acid to estimate reduced glutathione. The homogenate was then centrifuged at 2000 rpm for 10 minutes and the supernatant was used for the experimental analysis.

\section{Results and Discussion \\ Antioxidant levels in Mimosa pudica Enzymic and non-enzymic antioxidants}

The activity of the enzymic antioxidants such as superoxide dismutase, peroxidase, catechol oxidase and laccase were found to be present in the plant extract of Mimosa pudica. Superoxide dismutase activity was found to be maximum in the leaf sample followed by polyphenol oxidase. Peroxidase activity was found to be less when compared to superoxide dismutase. Polyphenol was found to be $5.3 \times 10$ Lipid peroxidation is a free radical mediated process and acts as a potential ${ }^{-3}$ units as catechol oxidase and laccase respectively (Table I). The presence of non-enzymic antioxidants in Mimosa pudica is illustrated in Table II and III; the levels of nonenzymic antioxidants (total phenols, flavonoids, $\mathrm{GSH}$, vitamin $\mathrm{C}$ and vitamin $\mathrm{E}$ are shown (Tables II and III).

\section{In vitro and in vivo inhibition of lipid peroxidation}

Free radical scavenging activity of different extracts of Mimosa pudica induced lipid peroxidation is depicted in Table IV. When different extracts of Mimosa pudica were compared for free radical, scavenging activity aqueous extract showed higher percentage of inhibition (89.73 \%) over ethanol, methanol, chloroform and petroleum ether extract. Based on the above results, water extract of Mimosa pudica was selected for its free radical scavenging activity. Lipid peroxidation is a free radical mediated process and acts as a potential marker of susceptibility of early and irreversible tissue damage. The hepatoprotective effect of Mimosa pudica against alcohol toxicity is presented in Table V. The levels of TBARS in liver were elevated in alcoholic group when compared with control group. Our study reveals that co-administration of Mimosapudica aqueous extract significantly lowered the level of lipid peroxidation in alcohol fed mice. The first line of cellular defense against free radicals consists of catalase, superoxide dismutase and peroxidase [11]. These enzymes react directly with oxygen radicals to yield non - radical products [12]. A significant reduction $(P<0.05)$ in the activity of antioxidant enzyme like SOD and catalase were observed in rats intoxicated with alcohol (Group II). But Co-administration with Mimosa pudica extract increases its activity. The enzyme antioxidant levels were increased when alcohol fed rats were treated with Mimosa pudica. Inhibition of SOD and catalase activities could be due to exhaustion or inactivation as a result of oxidative stress [13]. The increase in the SOD and Catalase activity by treatment with aqueous extract of Mimosa pudica effectively eliminates the super oxides and peroxides by alcohol intoxication. Table IV depicts the activity of Glutathione-S-transferase and Glutathione peroxidase. Recent studies have indicated that the cytosolic liver enzyme -glutathione Stransferase ( GST) functions as an early and sensitive indicator of hepatocyte damage caused by various adverse conditions, including hemorrhagic shock [14] ischemia and reperfusion[15] liver transplant rejection [16] and acetaminophen overdose [17]. Liver failure can be manifested by the increased level of GST or when GST remains persistently elevated [18]. Hepatocytes in severe alcoholic liver disease co expressed both alpha and pi class glutathione Stransferase [19]. The activity of Glutathione - Stransferase was considerably elevated in alcohol group than in other groups. Severe liver damage was observed on exposure to alcohol. On administration of Mimosa pudica extract the rat liver cells were protected from oxidative damage. GPx and GR activities in haemolysate decreased after 12 weeks of exposure to chronic ethanol treatment in mice [20]. The activity of GPx was significantly decreased in the liver of rats treated with alcohol. The decreased level of GPx can result in increased level of free radical [21] which induced lipid peroxidation [22]. Co-administration of Mimosa pudica showed the adaptive nature of the system against the damage of super oxide and peroxide radical. This agrees with the result of Omotuyi and Oluyemi who reported a decrease in Glutathione peroxidase which requires selenium for its optimum activity [23]. Selenium is decreased during increased free radical formation [24]. GSH antioxidant system consists of array of enzymic and non enzymic pathway involved in neutralisation of reactive free 
radical species [25]. Under conditions of increased oxidative stress to cells, levels of GSH are usually reduced [26]. The hepatoprotection was associated with the significant increase in hepatic GSH status, as indicated by substantial increase in tissue GSH levels in Mimosa pudica treated rats. From our finding it was observed that the activity of Vitamin $\mathrm{C}$ and reduced Glutathione decreased significantly in the liver tissues of animals administered with alcohol when compared to the control. Vitamins $\mathrm{C}$ and $\mathrm{E}$ are antioxidants that scavenge for free radicals [27]. The level of vitamin $\mathrm{C}$ and reduced glutathione was near normal when Mimosa pudica extract was fed with alcohol in rats. GSH, Vitamin $E$ and $C$ exist in their inter convertible forms and participate in the detoxification of the toxic reactive oxygen species [28]. So the present results indicate the protective potential offered by the Mimosa pudica extract against hepatic dysfunction caused by alcohol.

\author{
List of abbreviations \\ CAT - catalase \\ GPx - glutathione peroxidase \\ GR - glutathione reductase \\ GSH - reduced glutathione \\ GST - glutathione-S-transferase \\ SOD - superoxide dismutase \\ TBARS - thiobarbituric acid reactive substances
}

\section{References}

[1] Das S.K. and Vasudevan D.M. (2006) Indian J Clinical Biochem, 21(1), 62 69.

[2] Chatterjee M. and Sil P.C. (2007) Indian J Pharmacol, 39(3), (2007) $43-47$.

[3] Gupta S., Pandey R., Katyal R., Aggarwal H.K., Aggarwal R.P. and Aggarwal S.K. (2005) Indian J Clinical Biochem, 20(1), $67-71$

[4] Halliwell B. (1989) Br J Exp Pathol 70(2), $737-757$.

[5] Pandey M.M., Raghavan Govindarajan R., Rawat A.K. and Pushpangadan P. (2005) Acta Pharm 55(3), 297 - 304.

[6] Hasani P., Yasa N., Vosough-Ghanbari S., Mohammadirad, A., Dehghan G. and Abdollahi M. (2007) Acta pharm 57(2), $123-129$.

[7] Ganapathy P.M., (1995) Indian Medicinal Plants - a compendium of 500 species, Orient Longman Ltd Ed,. New Delhi, India.
[8] Motlhanka D.M.T. (2008) Pakistan J Biological Sci 11(5), 805 - 808.

[9] Arora A., Sairam R.K. and Srivastava G.C. (2002) Current Sci 82(18), 1227 - 1238.

[10] Nandhini G.D., Mitra A.G., Deshpande V.R. and Pahuja D. (1991) Indian J Biochem Biophys 29(3), $224-225$.

[11] Babu B.H. Shylesh B.S. and Dadikkala J. (2001) Fitoterpoia 72(2), 272 - 277

[12] Redl H., Schlag G., Paul E. and Davies J. (1995) Shock 3(1), 395-397.

[13] Wagensveld B.A., Scheepers J.J.G. and Gulik T. (1997) Transplant Proc 1997;29:3449-3451.

[14] Trull A.K., Facey S.P. and Rees G.W. (1994) Transplantation 58(3),13451351.

[15] Beckett G.J., Chapman B.J., Dyson E.H. and Hayes J.D. (1985) Gut 26(2), 26-31.

[16] Harrison D.J., May L., Hayes P.C., Haque M.M. and Hayes J.D. (1990) Gut. 31(8), 909-912.

[17] Das S.K., Varadhan S., Gupta G., Mukherjee S., Dhanya L., Rao D.N. and Vasudevan M. (2009) Indian J Biochem Biophys 46(1), 116-121.

[18] Johnston D.E. and Kroening C. (1998) Pharmacol Toxicol39(3), 231-239.

[19] Bhattacharyya D., Mukherjee R., Pandit S., Das, T.K. (2003) Indian J Pharmacol 35 (2) 183-185

[20] Chitra S., Suja V. and Shyamaladevi C.S. (2001) J Biomed 21(2\&3) 93-96.

[21] Irshad M. and Chauhuri P.S. (2002) Indian J Expt Biochem 40(2) 233 - 1239.

[22] Bhadauria M.M., Jadon A., Sharma A. and Shukla S. (2002) Indian J Expt Biol 40(2), $1254-1259$.

[23] Trivedi S. and Rawal U.M. (2000) J Pharmacol 7(3) 288 - 292.

[24] Suja V., Sharmila S.S. and Shyamaladevi C.S. (1997) Indian Expt Biol 35(3), 50 -52 .

[25] Wanger B.A. (1994) Biochemistry 33(5), 4449-4452.

[26] Hayes W. and Francis T. (2000) Principles and Methods of Toxicology 4th Ed., Philadelphia, USA.

[27] Omotuyi I.O., Oluyemi, K.A., Omofoma C.O., Josiah S.J., Adesanya O.A. and Saalu, L. C. (2006) African J Biotech 5 (20), 1909-1912. 
Table I- Levels of enzymic Antioxidants in Mimosapudica

\begin{tabular}{|c|c|c|c|c|}
\hline \multicolumn{4}{|c|}{ Enzymic Antioxidants } & \\
\hline \multicolumn{2}{|c|}{$\begin{array}{l}\text { Poly phenol oxidase units / g } \\
\text { tissue (PPO) }\end{array}$} & \multirow{2}{*}{$\begin{array}{l}\text { Superoxide } \\
\text { Dismutase } \\
\text { units/g tissue } \\
\text { (SOD) }\end{array}$} & \multirow[t]{2}{*}{$\begin{array}{l}\text { Peroxidase } \\
\text { units/g tissue }\end{array}$} & \\
\hline Catechol oxidase & Laccase & & & \\
\hline $5.3 \times 10^{-3}$ & $4.6 \times 10^{-3}$ & 172.78 & 0.966 & \\
\hline
\end{tabular}

SOD 1 unit = Amount of enzyme that gives $50 \%$ inhibition of the extent of NBT oxidation .

Table II- Levels of non-enzymic Antioxidants in Mimosapudica

\begin{tabular}{|l|l|l|l|}
\hline \multicolumn{4}{|c|}{ Non - Enzymic Antioxidants } \\
\hline $\begin{array}{l}\text { Total proteins } \\
\text { tissue }\end{array}$ & $\begin{array}{l}\text { Total Phenol } \\
\text { mg catechol/g } \\
\text { tissue }\end{array}$ & $\begin{array}{l}\text { Flavonoids } \mathrm{mg} / \mathrm{g} \\
\text { tissue }\end{array}$ & $\begin{array}{l}\text { GSH } \\
\text { nmoles/g } \\
\text { tissue }\end{array}$ \\
\hline 92.34 & 27.67 & 0.346 & 210.12 \\
\hline
\end{tabular}

Table III- Levels of non-enzymic Antioxidants in Mimosapudica

\begin{tabular}{|c|c|c|c|}
\hline $\begin{array}{l}\text { Non - Enzymic } \\
\text { Antioxidants }\end{array}$ & & & \\
\hline Vitamin $E \mu g / g$ tissue & $\begin{array}{l}\text { Vitamin } C \mu g / g \\
\text { tissue }\end{array}$ & $\begin{array}{l}\text { Tannins, } \\
\mathrm{mg} / \mathrm{g}\end{array}$ & tissue \\
\hline 175.81 & 5.67 & & 87.576 \\
\hline
\end{tabular}

Table IV-Effect of Mimosapudica on in vitro lipid peroxidation in ethanol induced rats

\begin{tabular}{|l|l|}
\hline Plant Extract & Percentage \\
\hline & inhibition \\
\hline Aqueous & $89.73 \%$ \\
\hline Alcohol & $82.88 \%$ \\
\hline Methanol & $80.23 \%$ \\
\hline Petroleum Ether & $40.34 \%$ \\
\hline Chloroform & $52.46 \%$ \\
\hline
\end{tabular}

Table V-Effect of Mimosapudica on lipid peroxidation and antioxidants in liver of rats

\begin{tabular}{|r|l|c|c|c|c|}
\hline S.NO & Parameters & Group I & Group II & Group III & Group IV \\
\hline 1 & SOD units & $7.626 \pm 0.07$ & $4.665 \pm 0.04 \mathrm{a}$ & $6.269 \pm 0.07 \mathrm{~b}$ & $6.558 \pm 0.02$ \\
\hline 2 & CAT units & $80.13 \pm 2.43$ & $55.18 \pm 0.84 \mathrm{a}$ & $73.18 \pm 0.70 \mathrm{~b}$ & $84.23 \pm 0.74$ \\
\hline 3 & GPX units & $4.36 \pm 0.04$ & $3.32 \pm 0.07 \mathrm{a}$ & $3.536 \pm 0.05 \mathrm{~b}$ & $4.142 \pm 0.09$ \\
\hline 4 & GST units & $1.934 \pm 0.02$ & $2.518 \pm 0.01 \mathrm{a}$ & $2.15 \pm 0.07 \mathrm{~b}$ & $1.811 \pm 0.07$ \\
\hline 5 & GSH (nmoles/g tissue) & $55.13 \pm 0.39$ & $0.31 \pm 0.08 \mathrm{a}$ & $48.08 \pm 0.23 \mathrm{~b}$ & $54.96 \pm 0.24$ \\
\hline 6 & Vit C (mg/g tissue) & $0.796 \pm 0.03$ & $1.95 \pm 4.36 \mathrm{a}$ & $0.57 \pm 0.11 \mathrm{~b}$ & $0.647 \pm 0.04$ \\
\hline 7 & LPO (nmoles of MDA/g tissue) & $1.18 \pm 0.05$ & & $1.45 \pm 0.12 \mathrm{~b}$ & $1.20 \pm 0.042$ \\
\hline & & & & & \\
\hline
\end{tabular}

(Values are mean \pm S.D. from 6 animals in each group)

Statistical Comparison a $\quad b=\operatorname{significant}(\mathrm{P}<0.05)$ when Group III is compared with Group II

significant $(P<0.05)$ when Group II is compared with Group I

significant $(P<0.05)$ when Group II is compared with Group I

$b=$ significant $(P<0.05)$ when Group III is compared with Group II

$\mathrm{a}=$ significant $(\mathrm{P}<0.05)$ when Group II is compared with Group I

$\mathrm{b}=\operatorname{significant}(\mathrm{P}<0.05)$ when Group III is compared with Group II

SOD- Units : $50 \%$ inhibition of nitrite $/ \mathrm{min} / \mathrm{mg}$ protein

Catalase- Units : n moles of $\mathrm{H} 2 \mathrm{O} 2$ decomposed $/ \mathrm{min} / \mathrm{mg}$ protein

GPx- Units : $\mathrm{n}$ moles of GSH / $\mathrm{min} / \mathrm{mg}$ protein

GST- Units : $\mathrm{n}$ moles of CDNB conjugated $/ \mathrm{min} / \mathrm{mg}$ protein 